\title{
Socioeconomic Inequalities in Metastasis, Recurrence, Stage, Grade, and Self-Rated Health of Gastrointestinal Cancer Patients
}

\author{
Majid Taheri ${ }^{1}$, Mahmoud Abbasi ${ }^{1}$, Mohammad Esmaeil Akbari ${ }^{2}$, Amir Almasi-Hashiani ${ }^{3,4}$ and \\ Mohammad Tavakol ${ }^{5, *}$ \\ ${ }^{1}$ Medical Ethics and Law Research Center, Shahid Beheshti University of Medical Sciences, Tehran, Iran \\ ${ }^{2}$ Cancer Research Center, Shahid Beheshti University of Medical Sciences, Tehran, Iran \\ ${ }^{3}$ Department of Epidemiology, School of Health, Arak University of Medical Sciences, Arak, Iran \\ ${ }^{4}$ Traditional and Complementary Medicine Research Center, Arak University of Medical Sciences, Arak, Iran \\ ${ }^{5}$ Sociology Department, School of Social Sciences, University of Tehran, Tehran, Iran \\ "Corresponding author: Sociology Department, School of Social Sciences, University of Tehran, Tehran, Iran. Email: mtavakol@ut.ac.ir
}

Received 2018 October 27; Revised 2019 February 23; Accepted 2019 March 02.

\begin{abstract}
Background: We evaluated the effect of socio-economic status (SES) inequality on metastasis, recurrence, stage, grade, and selfrated health (SRH) in patients with gastrointestinal cancers (GIC).

Methods: This cohort study was conducted on 409 patients suffering from GIC (April to October, 2018), who were referred to one of the hospitals of Arak University of Medical Sciences (Arak, Iran). They were entered to the study, using non-random sampling (accessible sampling). The SES was calculated by an asset-based questionnaire. The principle component analysis (PCA) was performed to estimate the household SES. The concentration index $(\mathrm{C})$ was used to measure the SES inequality, and the binary logistic regression was employed to investigate the association of recurrence and metastasis with other variables. The variance analysis was also used to investigate the relationship between SES and other variables. The data were analyzed with Stata (V.13) software.

Results: The total C index for metastasis, recurrence, stage, grade, SRH, and SRH-age was obtained as 0.089 (0.053, 0.121), -0.106 (-0.118, -0.065), 0.073 (0.069, 0.078), 0.035 (0.001, 0.051), 0.018 (0.010, 0.026), and 0.097 (0.063, 0.112), respectively. Moreover, the results of variance analysis showed a significant statistical association between SES and age, marital status, education, job, supplementary insurance, SRH-age, chemotherapy, and surgery $(\mathrm{P}<0.05)$.

Conclusions: Regarding the level of SES, the results of this study did not show the inequality in metastasis, recurrence, and stage. However, there was an inequality in grade and SRH by the SES levels in patients with GIC.
\end{abstract}

Keywords: Socio-Economic Status, Inequality, Concentration Index, Iran

\section{Background}

Gastrointestinal cancers (GIC) is one of the most common cancers worldwide. The mortality and morbidity caused by GIC are rising throughout the world and Asia (1). This type of cancer is one of the most dangerous and prevalent ones in Iran, causing about half of the deaths from cancers (2). The GIC causes many physical, social, and psychological problems for patients. Moreover, GIC causes many problems for the patients and their families, including the costs and economic issues (3).

Unfortunately, treatments are not effective on GICs diagnosed at advanced stage (4). According to various studies, some factors, including the grade of the tumor, metastasis to other organs, age, and gender, were identified as effective for GIC (5).

In recent decades, the research on the effect of socio- economic status (SES) inequalities on health has attracted increasing attention. According to various studies, the greatest burden of diseases and a large part of the health inequalities in the world are caused by social factors. The effect of some social determinants of health (SDH) on millennium development goals 1 and 2 was also considered (6). Determiners such as income inequity, employment, occupation, housing, education, nutrition, stress, and violence affect both the ability of people to develop diseases as well as their potential recovery from the disease (7). Surveys of the SDH in different parts of the world show the essential role of SES in the distribution of these diseases as well as their risk factors among socio-economic groups (8). In fact, such diseases have a particular social distribution pattern in various societies. In different societies, structural conditions (social and background factors) are re- 
sponsible for various health problems. The findings of the studies indicate that SDH have an impact on a wide range of health outcomes (cancers, cardiovascular diseases, and diabetes). In addition, the observed difference in the mortality rate of cancer is affected by social variables (9). The role of SES has also been proven in cancer survival. Reducing inequalities is an increasingly important focus of cancer control efforts, alongside improving survival overall. The role of SES and regional inequalities in survival from some types of GIC, such as colon and rectum cancer, have been observed in different studies (10-12). In addition, results showed that GIC was more prevalent in rural areas compared with urban ones, which can be due to low SES in the rural areas (13). Moreover, low SES is an important predictor of GIC survival and is directly related to it (14). Lower SES is generally associated with diagnosis at a later stage, and in some settings, poorer standards of care, less favorable health behaviors, and/or greater co-morbidity $(15,16)$.

Low SES can affect the diagnosis of cancer, which leads to diagnosis at the advanced stage and higher grade of cancer. A timely diagnosis that is related to the SES leads to diagnosis at a lower level and consequently prevents exaggeration, recurrence, and metastasis (17). Therefore, it is important to explain the role of the SES inequality in stage, grade, recurrence, and metastasis of the disease.

Nowadays, the $\mathrm{C}$ index is widely used in measuring health inequalities (18-20). This index indicates the inequality in health or the use of health services in a single number. The greater value of the $\mathrm{C}$ index, the higher degree of inequality (21). Moreover, this index is capable of decomposition, which means that the contribution level of various socio-economic variables can be obtained according to the level of inequality index. Therefore, variables that have the largest contribution in inequality are identified and can be prioritized in policymaking. The purpose of these studies is to identify the gaps and differences among diverse socioeconomic groups in achieving health services required for patients with cancer, so as to identify the causes of the differences and inequities, which ultimately, leads to a reduction in inequity in health services (22).

Self rated health (SRH) is an effective and popular way to define individual health. This method is widely used for its simplicity (23). Regarding the relationship between SRH and SES, individuals with low SES have a poor SRH (24). SRH can encourage individuals to follow a therapy or perform diagnostic and screening procedures (25). Therefore, it has an important role in preventing diseases and their deterioration (26).

Access to healthcare and screening is one of the important issues that have a positive effect on cancer prognosis and reduces metastasis and recurrence, which can be re- lated to SES inequality. In addition, the grade and stage of cancer, as well as the SRH are among factors that affect the progress of the disease. Up to now, no study has been performed to identify the role of SES inequalities in recurrence, metastasis, grade, and stage of disease, and SRH in of GIC.

\section{Objectives}

In this study, we evaluated the role of SES inequality in the recurrence and metastasis of GIC, regarding a C index approach in Arak, Iran.

\section{Methods}

\subsection{Sampling}

This cohort study was conducted on 409 patients suffering from GIC (April to October, 2018), who were referred to one of the hospitals of Arak University of Medical Sciences (Arak, Iran). They were entered to the study, using non-random sampling (accessible sampling). The protocol of the study was approved by the Ethics Committee of Shahid Beheshti University of Medical Sciences under grant number IR.SBMU.RETECH.REC.1396.839.

\subsection{Data Collection}

The required data were collected, using 3 questionnaires. (1) The personal, demographic, and disease information including age, gender, marital status, education, occupation, insurance, supplementary insurance, history of GIC in first degree relatives, history of chemotherapy, radiotherapy, and surgery, stage and grade of disease, recurrence, and metastasis. (2) SES questionnaire: Since the economic and social situation has widespread dimensions, there is no precise method for measuring it. Therefore, other alternatives are used (27), including house ownership, the number of rooms in the house, refrigerator, Television, mobile phone, washing machine, dishwasher, microwave oven, vacuum cleaner, computer, car, tablet, Internet access, air conditioner, water cooler, and radiator. The correlation of these factors with the total score and validity was 0.87 and 0.88 , respectively (28). (3) SRH questionnaire: SRH was examined by two questions: (A) "In general, what would you say about your health?” The answers were measured by a 5-point Likert type scale, ranging from excellent (score 1) to poor (score 5). (B) "How would you assess your general health status in comparison with your own age?" The answers were classified as much worse, worse, slightly worse, not better not worse, a little better, better, and much better. However, as coefficients of alternatives were close to each other in the regression analysis, SRH was 
divided into two groups of poor (quite poor, poor, middle) and good (good, excellent). SRH-age was also divided into two groups of poor (much worse, worse, slightly worse, not better not worse) and good (a little better, better, much better). This questionnaire was used by other studies, too (29, 30).

\subsection{Analysis}

In our study, the varimax rotated principal components analysis was used to calculate the SES. The principle component analysis (PCA) is a multivariate statistical technique for reducing a set of variables that are possibly correlated to a few non-interrelated variables called principle components. The first component, resulting from the analysis, explains the most variance among the variables in question and it is considered an index for the economic situation of each household. In fact, this component provides a score for each household, which reflects the household's economic situation and can be used in the analyses $(31,32)$.

In this study, the $\mathrm{C}$ index method was used for measuring inequality. The $C$ index is a variable between -1 and +1 . The negative values indicate that the variables (including metastasis, recurrence, grade, stage, SRH, and SRH-age) are concentrated on individuals with poor SES, but positive values indicate that these variables are concentrated among those with good SES. When the distribution of these variables is the same for all individuals, the $\mathrm{C}$ index will be zero $(33,34)$. The $\mathrm{C}$ index is a common inequity measure in health outcomes and it has been used continually in recent studies $(33,35,36)$. It was calculated, using a formula proposed by Kakwani Nanak et al. (33).

$C=\frac{2}{\mu} \sum_{t=1}^{T} f_{t} \mu_{t} R_{t}-1$

In this formula, $\mu$ is the mean of the SRH in studied patients, who were affected by cancer, and $\mu_{\mathrm{t}}$ is the same value for the $t^{\text {th }}$ group. In addition, $\mathrm{f}_{\mathrm{t}}$ is the group share of patients. $R_{t}$ is also the relative rank of the $t^{\text {th }}$ educational level of the participating patients, which was obtained through following formula:

$R_{t}=\sum_{t=1}^{T} f_{r}-\frac{1}{2} f_{t}$

Therefore, $R_{t}$ indicates the cumulative proportion up to the midpoint of each SES group interval. The corresponding confidence interval for $\mathrm{C}$ is calculated based on Wagstaff and Van Doorslaer method $(20,33,37)$. This method has been used in other studies, too $(20,33,37-40)$, and it is defined as follows:

$$
\begin{aligned}
\operatorname{Var}(C)= & \frac{1}{n}\left[\sum_{t=1}^{T} f_{t} a_{2}{ }^{2}-(1+C)\right] \\
& +\frac{1}{n \mu^{2}} \sum_{t=1}^{T} f_{t} \sigma_{t}{ }^{2}\left(2 R_{t}-1-C\right)^{2}
\end{aligned}
$$

In this formula, $\sigma_{\mathrm{t}}{ }^{2}$ is the variance of $\mu_{\mathrm{t}}$,

$a_{t}=\frac{\mu_{t}}{\mu}\left(2 R_{t}-1-C\right)+2-q_{r-1}-q_{t}$, and $q_{t}=$ $\frac{1}{\mu} \sum_{r}^{t} \mu_{r} f_{r}$ which is the ordinate of $\mathrm{L}(\mathrm{P}), \mathrm{q}_{0}=0$ and $p_{t}=$ $\sum_{r=1}^{t} f_{r} R_{r}$

The binary logistic regression was used to investigate the association of recurrence and metastasis with other variables in the study. This method calculates the value of odds ratio (OR) for each variable while removing the effect of other ones. Moreover, the variance analysis and the significance level of $95 \%$ were used to investigate the relationship between SES and other variables. All statistical analyses were performed, using Stata (V.13) software.

\section{Results}

Using the binary logistic regression, the association of crude and adjusted OR and their confidence interval of recurrence with other variables was investigated, and the results were shown in Table 1. Based on these results, the OR estimate of recurrence was 0.86 (95\% CI: 0.84, 0.89) among patients with supplementary insurance, compared to those who lacked the supplementary insurance. Compared to patients with poor SRH-age, the OR estimate of recurrence was 3.63 (95\% CI: 1.56, 8.48) among those with good SRH-age. Compared to patients affected by stage one of GIC, the OR estimate of recurrence was 9.86 (95\% CI:1.00, 98.92) among those suffering from stage 4 . The OR estimate of recurrence was 7.05 (95\% CI:1.99, 24.93) among patients with grade 3 compared to those with grade 1 .

Using the binary logistic regression, the association of crude and adjusted OR and their confidence interval of metastasis with other variables was investigated, and the results were shown in Table 2. Based on these results, the OR estimate of metastasis was 3.25 (95\% CI: 1.05, 10.08) in patients over 60 years old, compared to those under 40 years old. The OR estimate of metastasis was 4.03 (95\% CI: $1.96,8.28$ ) in male patients compared to female ones. Compared to the illiterate level of education, the OR estimate of metastasis was 3.39 (95\% CI:1.22, 9.43) in academic level. Compared with patients who lacked insurance, the OR estimate of metastasis was 0.15 (95\% CI: 0.02, 0.93) among those with insurance. Compared to patients with poor SRH, the OR estimate of metastasis was 0.35 (95\% CI: 0.10, 0.99 ) among those with good SRH. In comparison with patients without surgery, the OR estimate of metastasis was 0.43 (95\% CI: $0.23,0.82)$ in those with surgery. Compared to 


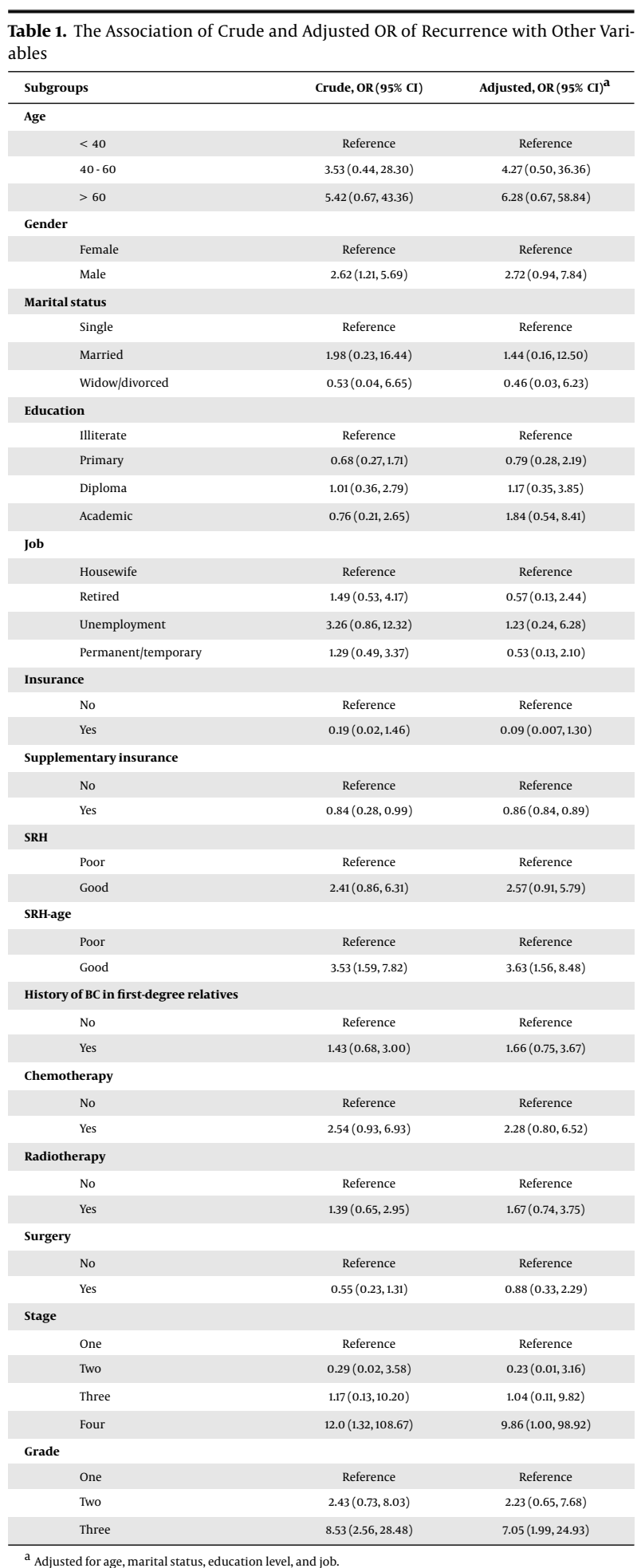

patients affected by stage 1 of GIC, the OR estimate of metastasis was 3.17 (95\% CI: 2.01, 7.43) among those with stage 3, and was 5.25 (95\% CI: 4.81,16.34) among those who suffered from stage 4. The OR estimate of metastasis was 4.64 (95\% CI: $2.06,10.46)$ among patients with grade 2 , and was 9.76 (95\% CI: 3.92, 24.30) among those with grade 3, compared to those affected by grade 1 .

The relationship between SES and other variables are shown in Table 3. Results of analysis of variance showed the significant statistical relationship of SES with supplementary insurance, SRH-age, chemotherapy, and surgery ( $\mathrm{P}<$ 0.05).

The $C$ index was obtained as $-0.0188(-0.0392,0.0016)$ and -0.0484 (-0.1352, 0.0383) for recurrence and metastasis, respectively. In addition, the $\mathrm{C}$ index for grade, stage, $\mathrm{SRH}$, and SRH-age of GIC was obtained as -0.019 (-0.030,-0.0091), $-0.010(-0.021,0.0004), 0.0055$ (0.0001, 0.0109), and -0.044 $(-0.0525,-0.0355)$, respectively. According to these results, there was no concentration of metastasis and grade regarding the SES levels (Table 4). However, there was concentration of higher stage and SRH-age in lower SES levels, and there was concentration of SRH in higher SES levels.

\section{Discussion}

The main findings of our study included the effect of supplementary insurance, SRH-age, stage 4 , and grade 3 on the recurrence of the GIC $(\mathrm{P}<0.05)$. Also, there was an association between recurrence and age, gender, academic level of education, insurance, SRH, surgery, stage 3, stage 4, grade 2 , and grade $3(\mathrm{P}<0.05)$. The SES levels had an effect on supplementary insurance, SRH-age, chemotherapy, and surgery $(P<0.05)$. There was no concentration of metastasis, recurrence, and stage, while there was some concentration of grade, SRH, and SRH-age regarding the SES levels.

The findings of this study showed that there was no significant relationship between recurrence of GIC and age of patients. According to some studies, age is an important factor in the prognosis of a variety of cancers (41). The results of our study are similar to those of other investigations $(42,43)$. The relationship between gender and metastasis of GIC was observed in our study. In a study on singlevariable analysis of information, gender had a significant relationship with deterioration and death due to GIC, and men were more likely to die from colon and rectal cancer compared with women. However, in a multivariate model, there was no significant relationship between gender and survival in both cancer cases (44). A study by Wei et al. also confirms this conclusion (45). Park et al. reported a significant relationship between gender and death due to rectal cancer. However, this relationship was not significant for colon cancer (46).

Supplementary insurance was proved to be a significant and protective factor for metastasis and recurrence of GIC. Supplementary insurance can be considered a factor 


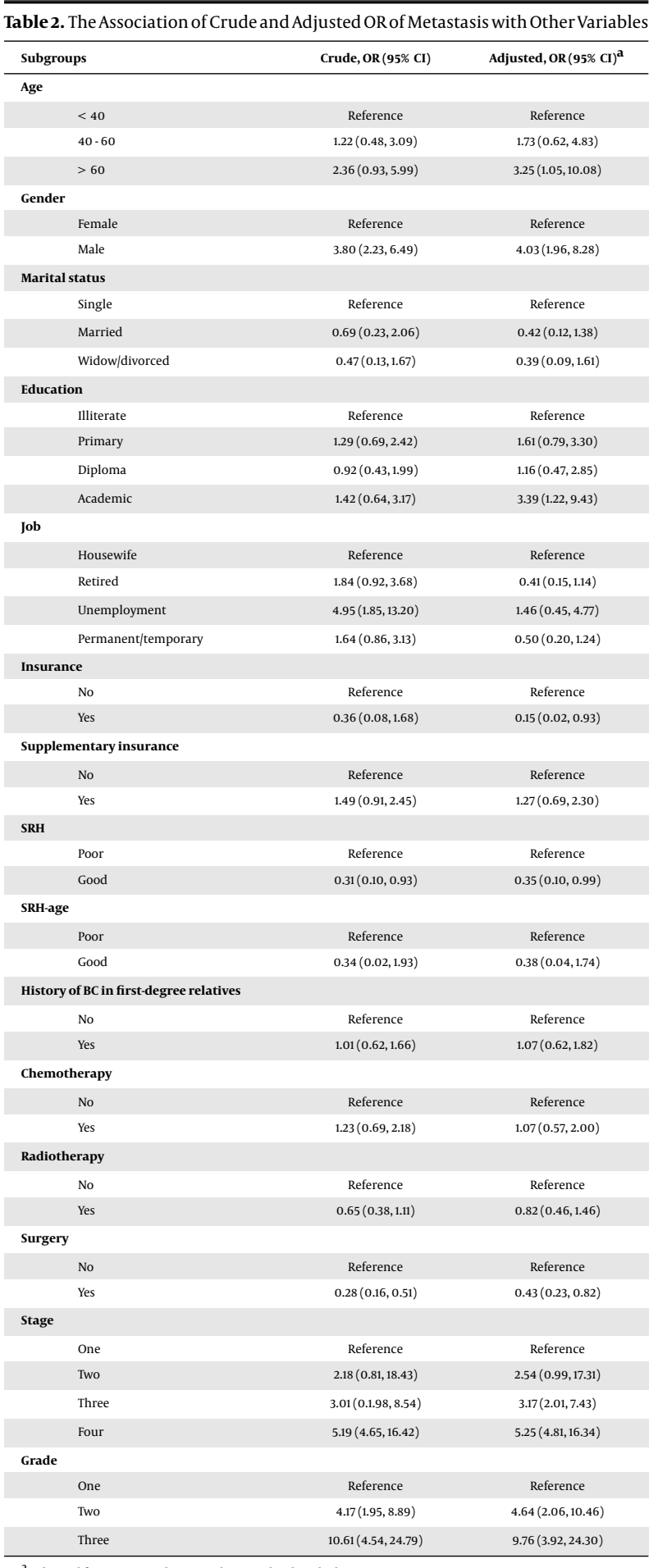

a Adjusted for age, marital status, education level, and job.

in the prevention and treatment of disease. The effect of insurance on GIC was evaluated in various studies. In a study conducted by Shin et al., titled "Impact of Supplementary

\begin{tabular}{|c|c|c|}
\hline Subgroups & Mean \pm SD & PValue \\
\hline Insurance & & 0.142 \\
\hline No & $-0.37 \pm 1.13$ & \\
\hline Yes & $0.05 \pm 0.98$ & \\
\hline Supplementary insurance & & $<0.001$ \\
\hline No & $-0.12 \pm 0.93$ & \\
\hline Yes & $0.25 \pm 0.99$ & \\
\hline SRH & & 0.303 \\
\hline No & $0.02 \pm 0.99$ & \\
\hline Yes & $0.18 \pm 0.90$ & \\
\hline SRH-age & & $<0.001$ \\
\hline No & $0.31 \pm 0.96$ & \\
\hline Yes & $-0.17 \pm 0.94$ & \\
\hline Chemotherapy & & $<0.05$ \\
\hline No & $-0.111 \pm 0.86$ & \\
\hline Yes & $0.119 \pm 1.03$ & \\
\hline Radiotherapy & & 0.595 \\
\hline No & $0.02 \pm 1.00$ & \\
\hline Yes & $0.08 \pm 0.94$ & \\
\hline Surgery & & $<0.05$ \\
\hline No & $-0.19 \pm 0.95$ & \\
\hline Yes & $0.10 \pm 0.98$ & \\
\hline Grader & & 0.121 \\
\hline One & $0.20 \pm 0.90$ & \\
\hline Two & $-0.04 \pm 0.94$ & \\
\hline Three & $0.13 \pm 1.13$ & \\
\hline Stage & & 0.107 \\
\hline One & $-0.18 \pm 0.64$ & \\
\hline Two & $0.23 \pm 1.01$ & \\
\hline Three & $0.11 \pm 0.90$ & \\
\hline Four & $-0.11 \pm 1.03$ & \\
\hline Recurrence & & 0.750 \\
\hline No & $0.05 \pm 0.93$ & \\
\hline Yes & $0.11 \pm 0.95$ & \\
\hline Metastasis & & 0.224 \\
\hline No & $0.14 \pm 0.91$ & \\
\hline Yes & $-0.00 \pm 1.05$ & \\
\hline
\end{tabular}

Abbreviation: SRH, self rated health.

Table 4. Calculation of $\mathrm{C}$ Indexes and Their Equivalent 95\% CI, for Metastasis, Recurrence, Stage, and Grade of BC Patients

\begin{tabular}{lcc}
\hline Outcomes & Concentration Index & 95\% Confidence Intervals \\
\hline Recurrence & -0.0188 & $-0.0392,0.0016$ \\
\hline Metastasis & -0.0484 & $-0.1352,0.0383$ \\
\hline Stage & -0.010 & $-0.021,0.0004$ \\
Grade & -0.019 & $-0.030,-0.0091$ \\
\hline SRH & 0.005 & $0.0001,0.0109$ \\
\hline SRH-age & -0.044 & $-0.0525,-0.0355$ \\
\hline
\end{tabular}

Abbreviation: SRH, self rated health.

Private Health Insurance on Stomach Cancer Care in Ko- 
rea", they concluded that supplementary private health insurance had no effect on the treatment process and the patient's condition (47). In another study, it was shown that there was a statistically significant relationship between health insurance and the average quality of life in patients with GIC, such as colon cancer (48). Previous studies have shown that patients without health insurance have less access to health care and prevention services such as cancer screening and are more likely to be diagnosed with cancer at advanced stage (49). This can be a factor, which increases metastasis. People who have insurance, benefit from a better quality of life and are more satisfied with health services. The existence of supplementary insurance in Iran could play an effective role in increasing the patient's referral to the physician for care and treatment (50).

Extensive studies have identified a number of genes, each of which causes metastases in different tissues. According to the different conditions of each organ, these genes can explain the distribution of metastasis in different organs (51). In this study, the grade and stage of disease played a strong and significant role in the recurrence and metastasis of GIC. According to a previous study, the grade of the disease was an important factor in predicting the relative risk of metastasis (52). In a study by Elston and Ellis the grade of the tumor was reported as a significant factor, and it was shown that patients with grade 1 had a greater survival compared to those with grade 2 and 3 (53). Another issue that may be raised regarding the relationship of the grade of GIC with recurrence and metastasis is the size of the tumor. In some studies, the size of the tumor has been shown as a prognostic factor in the survival of patients (54).

According to the results of a previous study, there is a long-standing relationship between economic variables and the demand for supplementary treatment insurance. The findings of this study also showed that national income per capita and literacy rates have a positive and significant relationship with the demand for supplementary insurance (55). Emamian et al. evaluated the role of SES inequality in risk factors of non-communicable disease in Iran. Their results showed the concentration of these factors in the lowest SES. The most important factors that affect these inequalities included age, marital status, job, and living in rural areas (56).

SRH as an indicator on the international level may be considered as the best index of a person's health status. The results of this study showed that GIC patients with good SRH had more chance of recurrence and less chance of metastasis compared with those with poor SRH. Another kind of SRH was evaluated in this study, in which the health of GIC patients was evaluated in comparison with that of the same age group. The result of the variance and $\mathrm{C}$ in- dex analysis of the association of both types of SRH with SES showed that patients with a good SES have a good SRH, too. The concentration of good SRH was also better on good SES. Although the relationship of SRH with recurrence and metastasis was not significant, the relationship between SRH and health has been proven in different studies. One of the things that can explain the role of SRH in recurrence and metastasis is the effect of age on SRH. Based on the results of a study, the increase in age is an effective factor in poor SRH. This finding is corroborated by the results of previous studies in Asia and Europe, which demonstrated that reducing the level of health is associated with age (57-59). SRH is also known as a predictor of death (60). Therefore, it can be concluded that by increasing the age, the SRH decreases. On the other hand, the relationship of age with recurrence and metastasis has been proven in our study. Therefore, by increasing the age, the amount and chance of recurrence and metastasis of SRH decreases.

According to the results of this study, the role of SES inequality was evident in factors related to GIC such as grade, SRH, and SRH-age. This was the first study to examine SES inequality in these factors. However, the role of SES inequality in health status has been addressed in other studies (61-63). One of the important factors affecting cancer is the economic situation. Individuals with high SES use more diagnostic and therapeutic tests and health services, which leads to the early detection of cancer (64). If the disease is diagnosed at the beginning stage, there will certainly be less recurrence and metastasis. Another study showed that income inequality is one of the most important factors affecting the health of individuals (65). Regarding SES inequality in SRH, it can be concluded that individuals measure their well-being in comparison to the average welfare of their community, and when they have less access to economic resources compared with others, they feel retarded. This issue affects people's attitudes, behaviors, and mental health. Psychosocial stresses and highrisk behaviors play an important role in the incidence of various diseases (66). Income inequality is associated with inequality in education, access to drinking water, health facilities, nutrition, and disease outbreaks, which affect people's health (67). Therefore, SES inequality has an important effect on health, prevention of diseases, and the prevention of deterioration of chronic diseases such as cancers.

\subsection{Conclusions}

Considering the fact that there has been no study on the role of SES inequality in recurrence, metastasis, grade and stage of GIC, SRH, and SRH-age so far, our study can demonstrate the importance of this topic. Metastasis in patients with cancer is very important because it is one of the 
most important factors for cancer survival. Patients with cancer without metastasis have more life expectancy and survival. Recurrence and grade of disease are also important factors in survival from cancer. Moreover, SRH plays an important role in early diagnosis and treatment of cancer.

\section{Acknowledgments}

The present study was part of a thesis submitted by the first author for a Ph.D. degree in Medical Sociology and it was funded by Shahid Beheshti University of Medical Sciences. Hereby, the authors appreciate all oncologists, who helped with conducting the current project. We would also like to thank all patients, who participated in this research.

\section{Footnotes}

Authors' Contribution: All the authors meet the standard authorship criteria according to the recommendations of international committee of medical journal editors.

Conflict of Interests: It is not declared by the authors. Ethical Approval: The Research Ethics Committee of Shahid Beheshti University of Medical Sciences approved this study (Ethical Code: IR.SBMU.RETECH.REC.1396.839).

Financial Disclosure: It is not declared by the authors.

Funding/Support: This research has been supported by Shahid Beheshti University of Medical Sciences grant number: 11361.

Patient Consent: The participants provided written informed consent for voluntary participation in the study.

\section{References}

1. Sung JJ, Ng EK, Lin JT, Ho KY, Ji JF, Sugano K, et al. Digestive cancer management in Asia: Position statements: A report on GI oncology summit in 2011. J Gastroenterol Hepatol. 2012;27(9):1417-22. doi: 10.1111/j.1440-1746.2012.07194.x. [PubMed: 22694174].

2. Biglu MH, Tabatabaei S. [Gastrointestinal cancers in Iran: Iranian scientists approach to gastrointestinal cancers researches in international databases]. Koomesh. 2017;19(1). Persian.

3. Hasanpoor Dehkordi A, Azari S. [Quality of life and related factor in cancer patients]. Behbood. 2006;10:110-9. Persian.

4. Naghavi M. [Death report from 10 provinces in Iran]. Tehran: Ministry of Health; 2000. Persian.

5. Ghadimi MR, Mahmoodi M, Mohammad K, Zeraati H, Hosseini M, Sheikh Fathollahi M. Comparison of survival analysis of gastrointestinal cancer patients using parametric and Cox models. J School Public Health Inst Public Health Res. 2010;8(2):1-14.

6. Ranjbar Ezzatabadi M, Khosravi A, Bahrami MA, Rafiei S. Socioeconomic inequalities in health services utilization: A cross-sectional study. Int J Health Care Qual Assur. 2018;31(1):69-75. doi: 10.1108/IJHCQA04-2017-0059. [PubMed: 29504844].
7. Truesdale BC, Jencks C. The health effects of income inequality: Averages and disparities. Annu Rev Public Health. 2016;37:413-30. doi: 10.1146/annurev-publhealth-032315-021606. [PubMed: 26735427].

8. Muchukuri E, Grenier FR. Social determinants of health and health inequities in Nakuru (Kenya). Int J Equity Health. 2009;8:16. doi: 10.1186/1475-9276-8-16. [PubMed: 19439105]. [PubMed Central: PMC2687433].

9. Gilson L, Doherty J, Loewenson R, Francis V. Challenging inequity through health systems. Final report of the knowledge network on health systems. 2007.

10. Byers TE, Wolf HJ, Bauer KR, Bolick-Aldrich S, Chen VW, Finch JL, et al. The impact of socioeconomic status on survival after cancer in the United States : Findings from the National Program of Cancer Registries Patterns of Care Study. Cancer. 2008;113(3):582-91. doi: 10.1002/cncr.23567. [PubMed: 18613122].

11. Dejardin O, Bouvier AM, Faivre J, Boutreux S, De Pouvourville G, Launoy G. Access to care, socioeconomic deprivation and colon cancer survival. Aliment Pharmacol Ther. 2008;27(10):940-9. doi: 10.1111/j.1365-2036.2008.03673.x. [PubMed: 18315583].

12. Eloranta S, Lambert PC, Cavalli-Bjorkman N, Andersson TM, Glimelius B, Dickman PW. Does socioeconomic status influence the prospect of cure from colon cancer-a population-based study in Sweden 19652000.EurJCancer.2010;46(16):2965-72. doi:10.1016/j.ejca.2010.05.028. [PubMed: 20580545].

13. Yazdanbod A, Samadi F, Babaei M, Malekzadeh R, Iranparvar AM, Azami A. [Four-year survival rate of patients with upper GI cancer in Ardabil]. J Ardabil Univ Med Sci. 2005;5(16):180-4. Persian.

14. Fontana V, Decensi A, Orengo MA, Parodi S, Torrisi R, Puntoni R. Socioeconomic status and survival of gastric cancer patients. Eur J Cancer. 1998;34(4):537-42. doi: 10.1016/S0959-8049(97)10098-3. [PubMed: 9713305].

15. Aarts MJ, Lemmens VE, Louwman MW, Kunst AE, Coebergh JW. Socioeconomic status and changing inequalities in colorectal cancer? A review of the associations with risk, treatment and outcome. Eur J Cancer. 2010;46(15):2681-95. doi: 10.1016/j.ejca.2010.04.026. [PubMed: 20570136].

16. Palmer RC, Schneider EC. Social disparities across the continuum of colorectal cancer: A systematic review. Cancer Causes Control. 2005;16(1):55-61. doi: 10.1007/s10552-004-1253-3. [PubMed: 15750858].

17. Le H, Ziogas A, Lipkin SM, Zell JA. Effects of socioeconomic status and treatment disparities in colorectal cancer survival. Cancer Epidemiol Biomarkers Prev. 2008;17(8):1950-62. doi: 10.1158/1055-9965.EPI07-2774. [PubMed: 18708384].

18. van Doorslaer E, Koolman X, Jones AM. Explaining income-related inequalities in doctor utilisation in Europe. Health Econ. 2004;13(7):62947. doi: 10.1002/hec.919. [PubMed:15259043].

19. Wagstaff A, Paci P, van Doorslaer E. On the measurement of inequalities in health. Soc Sci Med. 1991;33(5):545-57. doi: 10.1016/02779536(91)90212-U. [PubMed: 1962226].

20. Wagstaff A, Van Doorslaer E. Measuring inequalities in health in the presence of multiple-category morbidity indicators. Health Econ. 1994;3(4):281-9. doi: 10.1002/hec.4730030409. [PubMed: 7994327].

21. Wagstaff A, Paci P, Joshi H.Inequalities in health: Who you are? Where you live? Or who your parents were? Evidence from a cohort of British 33-yearolds. Washington (DC): World Bank; 2001. doi: 10.1596/1813-9450-2713.

22. Smits J, Monden C. Length of life inequality around the globe. Soc Sci Med. 2009;68(6):1114-23. doi: 10.1016/j.socscimed.2008.12.034. [PubMed: 19176269].

23. Robine JM, Jagger C, Romieu I. Selection of a coherent set of health indicators for the European Union. Phase II: Final report. Montpellier: France: Euro-REVES; 2002.

24. Tsimbos C. An assessment of socio-economic inequalities in health among elderly in Greece, Italy and Spain. Int J Public Health. 2010;55(1):5-15. doi: 10.1007/s00038-009-0083-1. [PubMed: 19806317]. 
25. Manton KG. Recent declines in chronic disability in the elderly U.S. population: Risk factors and future dynamics. Annu Rev Public Health. 2008;29:91-113. doi: 10.1146/annurev.publhealth.29.020907.090812. [PubMed: 18031222].

26. McCullough ME, Laurenceau JP. Gender and the natural history of self-rated health: A 59-year longitudinal study. Health Psychol. 2004;23(6):651-5. doi: 10.1037/0278-6133.23.6.651. [PubMed: 15546234].

27. Moradi G, Mohammad K, Majdzadeh R, Ardakani HM, Naieni KH. Socioeconomic inequality of non-communicable risk factors among people living in Kurdistan province, Islamic Republic of Iran. Int J Prev Med. 2013;4(6):671-83. [PubMed: 23930185]. [PubMed Central: PMC3733035].

28. Garmaroudi GR, Moradi A. Socio-economic status in Iran: A study ofmeasurement index. 2010.

29. BombakAE. Self-rated health and public health: A critical perspective. Front Public Health. 2013;1:15. doi: 10.3389/fpubh.2013.00015. [PubMed: 24350184]. [PubMed Central: PMC3855002].

30. Haddock CK, Poston WS, Pyle SA, Klesges RC, Vander Weg MW, Peterson A, et al. The validity of self-rated health as a measure of health status among young military personnel: Evidence from a cross-sectional survey. Health Qual Life Outcomes. 2006;4:57. doi: 10.1186/1477-7525-457. [PubMed: 16939653]. [PubMed Central: PMC1569825].

31. Filmer D, Pritchett LH. Estimating wealth effects without expenditure data-or tears: An application to educational enrollments in states of India. Demography. 2001;38(1):115-32. [PubMed: 11227840].

32. Vyas S, Kumaranayake L. Constructing socio-economic status indices: how to use principal components analysis. Health Policy Plan. 2006;21(6):459-68. doi: 10.1093/heapol/czl029. [PubMed: 17030551].

33. Kakwani Nanak C, Wagstaff A, van Doorslaer E. Socioeconomic inequalities in health: Measurement, computation, and statistical inference. J Econ. 1997;77(1):87-103. doi:10.1016/s0304-4076(96)01807-6.

34. Kakwani Nanak C, Kakwani Nanak C. Income inequality and poverty: Methods of estimation and policy applications. Oxford University Press; 1980.

35. Hassanzadeh J, Mohammadbeigi A, Eshrati B, Rezaianzadeh A, Rajaeefard A. Determinants of inequity in health care services utilization in Markazi province of Iran. Iran Red Crescent Med J. 2013;15(5):36370. doi: 10.5812/ircmj.3525. [PubMed: 24349720]. [PubMed Central: PMC3838642].

36. Ramezani Doroh V, Vahedi S, Arefnezhad M, Kavosi Z, Mohammadbeigi A. Decomposition of health inequality determinants in Shiraz, south-west Iran. J Res Health Sci. 2015;15(3):152-8. [PubMed: 26411660].

37. Mohammadbeigi A, Hassanzadeh J, Eshrati B, Mohammadsalehi N. [Inequity in health; measurement indexes and application to the health care utilization data]. Iran JEpidemiol. 2013;9(2):1-14. Persian.

38. Mohammadbeigi A, Arsangjang S, Mohammadsalehi N, Anbari Z, Ghaderi E. Education-related inequity in access and utilization of oral health care in Iran. J Family Med Prim Care. 2015;4(1):35-8. doi:10.4103/2249-4863.152248. [PubMed: 25810987]. [PubMed Central: PMC4367004].

39. Mohammadbeigi A, Hassanzadeh J, Eshrati B, Rezaianzadeh A. Decomposition of inequity determinants of healthcare utilization, Iran. Public Health. 2013;127(7):661-7. doi: 10.1016/j.puhe.2013.01.001. [PubMed: 23608021].

40. Mohammadbeigi A, Hassanzadeh J, Eshrati B, Rezaianzadeh A. Socioeconomic inequity in health care utilization, Iran. J Epidemiol Glob Health.2013;3(3):139-46. doi:10.1016/j.jegh.2013.03.006. [PubMed: 23932056].

41. Jalali M, Jaseb K, Velaee N. [Age and type of tumorigenicity with prognosis of breast cancer patients]. Feyz Sci J. 2000;20:67-73. Persian.

42. Matthews RH, McNeese MD, Montague ED, Oswald MJ. Prognostic implications of age in breast cancer patients treated with tumorectomy and irradiation or with mastectomy. Int J Radiat Oncol Biol Phys. 1988;14(4):659-63. doi: 10.1016/0360-3016(88)90086-7.

43. Noyes RD, Spanos WJ, Montague ED. Breast cancer in women aged 30 and under. Cancer. 1982;49(6):1302-7. doi: 10.1002/1097-
0142(19820315)49:6<1302::AID-CNCR2820490638>3.0.CO;2-0. [PubMed: 6174202].

44. Akhoond M, Kazemnejad A, Hajizadeh E, Ganbary Motlagh A, Zali M. [Comparison of influential factors affecting survival of patients with colon and rectum cancer using competing risks model]. Koomesh. 2010;12(2):119-28. Persian.

45. Wei EK, Giovannucci E, Wu K, Rosner B, Fuchs CS, Willett WC, et al. Comparison of risk factors for colon and rectal cancer. Int J Cancer. 2004;108(3):433-42. doi: 10.1002/ijc.11540. [PubMed: 14648711]. [PubMed Central: PMC2903217].

46. Park YJ, Park KJ, Park JG, Lee KU, Choe KJ, Kim JP. Prognostic factors in 2230 Korean colorectal cancer patients: Analysis of consecutively operated cases. World J Surg.1999;23(7):721-6. doi:10.1007/PL00012376. [PubMed: 10390594].

47. Shin DW, Jung KT, Kim S, Bae JM, Kim YW, Ryu KW, et al. Impact of supplementary private health insurance on stomach cancer care in Korea: A cross-sectional study. BMC Health Serv Res. 2009;9:133. doi: 10.1186/1472-6963-9-133. [PubMed: 19643032]. [PubMed Central: PMC2726135].

48. Momeni M, Ghanbari Khanghah A, Joukar F, Kazem Nezhad LE. [Predictive factors of quality of life in patients with colorectal cancer].J Hol Nurs Midwifery. 2012;22(1):44-53. Persian.

49. Halpern MT, Ward EM, Pavluck AL, Schrag NM, Bian J, Chen AY. Association of insurance status and ethnicity with cancer stage at diagnosis for 12 cancer sites: A retrospective analysis. Lancet Oncol. 2008;9(3):222-31. doi: 10.1016/S1470-2045(08)70032-9. [PubMed: 18282806]

50. Ferdosi M, Mohammadi Zadeh M. [Satisfaction level of insurance and supplementary insurance in patients].J Health Manage. 2003;2(1):4653. Persian.

51. Noori R, Daloii M, Fazilaty M, Tabrizi H. [Cancer metastasis, genetic and microenvironmental factors of distant tissue: A review article] Tehran Univ Med J. 2013;70(11). Persian.

52. Gohari MR, Abolghasemi J, Mohammadi M. [Prognostic factors of metastases in breast cancer patients using the recurrent AndersenGill model]. Koomesh. 2013;14(4):483-9. Persian.

53. Elston CW, Ellis IO. Pathological prognostic factors in breast cancer. I. The value of histological grade in breast cancer: Experience from a large study with long-term follow-up. Histopathology. 1991;19(5):40310. doi: 10.1111/j.1365-2559.1991.tb00229.x. [PubMed: 1757079].

54. Heitz F, Rochon J, Harter P, Lueck HJ, Fisseler-Eckhoff A, Barinoff J, et al. Cerebral metastases in metastatic breast cancer: Disease-specific risk factors and survival. Ann Oncol. 2011;22(7):1571-81. doi: 10.1093/annonc/mdq625. [PubMed: 21059640].

55. Abbasi E, Taghi Abadi M. [The effect of economic factors on patient satisfaction]. Insurance J. 2011;26(4):57-80. Persian.

56. Emamian MH, Alami A, Fateh M. [Socioeconomic inequality in noncommunicable disease risk factors in Shahroud, Iran]. Iran J Epidemiol. 2011;7(3):44-51. Persian.

57. Asfar T, Ahmad B, Rastam S, Mulloli TP, Ward KD, Maziak W. Self-rated health and its determinants among adults in Syria: A model from the Middle East. BMC Public Health. 2007;7:177. doi: 10.1186/1471-2458-7-177. [PubMed: 17651491]. [PubMed Central: PMC1976325].

58. Li ZB, Lam TH, Ho SY, Chan WM, Ho KS, Li MP, et al. Age- versus timecomparative self-rated health in Hong Kong Chinese older adults. Int J Geriatr Psychiatry. 2006;21(8):729-39. doi: 10.1002/gps.1553. [PubMed: 16858746].

59. McFadden E, Luben R, Bingham S, Wareham N, Kinmonth AL, Khaw KT. Social inequalities in self-rated health by age: Cross-sectional study of 22,457 middle-aged men and women. BMC Public Health. 2008;8:230. doi: 10.1186/1471-2458-8-230. [PubMed: 18611263]. [PubMed Central: PMC2491612].

60. Lyyra TM, Leskinen E, Jylha M, Heikkinen E. Self-rated health and mortality in older men and women: A time-dependent covariate analysis. Arch Gerontol Geriatr. 2009;48(1):14-8. doi: 
10.1016/j.archger.2007.09.004. [PubMed: 17950481].

61. Hosseinpoor AR, Mohammad K, Majdzadeh R, Naghavi M, Abolhas sani F, Sousa A, et al. Socioeconomic inequality in infant mortality in Iran and across its provinces. Bull World Health Organ. 2005;83(11):83744. [PubMed: 16302040]. [PubMed Central: PMC2626462].

62. Kushel MB, Vittinghoff E, Haas JS. Factors associated with the health care utilization of homeless persons. JAMA. 2001;285(2):200-6. doi: 10.1001/jama.285.2.200. [PubMed: 11176814]

63. Van de Poel E, Hosseinpoor AR, Speybroeck N, Van Ourti T, Vega J. Socioeconomic inequality in malnutrition in developing countries. Bull World Health Organ. 2008;86(4):282-91. doi: 10.2471/BLT.07.044800. [PubMed: 18438517]. [PubMed Central: PMC2647414].

64. Myers ER, Moorman P, Gierisch JM, Havrilesky LJ, Grimm LJ, Ghate $S$, et al. Benefits and harms of breast cancer screening: A system- atic review. JAMA. 2015;314(15):1615-34. doi: 10.1001/jama.2015.13183. [PubMed: 26501537].

65. Mohammadzadeh Y, Hasanzadeh K. [Determinants of health and the cost of catastrophic health expenses in households].JTehran Univ Med Sci. 2016;11:221-33. Persian.

66. Idrovo AJ, Ruiz-Rodriguez M, Manzano-Patino AP. Beyond the income inequality hypothesis and human health: A worldwide exploration. Rev Saude Publica. 2010;44(4):695-702. doi: 10.1590/S003489102010005000020. [PubMed: 20585742].

67. Brinda EM, Rajkumar AP, Enemark U, Prince M, Jacob KS. Nature and determinants of out-of-pocket health expenditure among older people in a rural Indian community. Int Psychogeriatr. 2012;24(10):1664-73. doi: 10.1017/S104161021200083X. [PubMed: 22613070]. 